Tade M. Spranger

\title{
Recht und Bioethik
}

\section{Verweisungszusammenhänge bei der Normierung der Lebenswissenschaften}

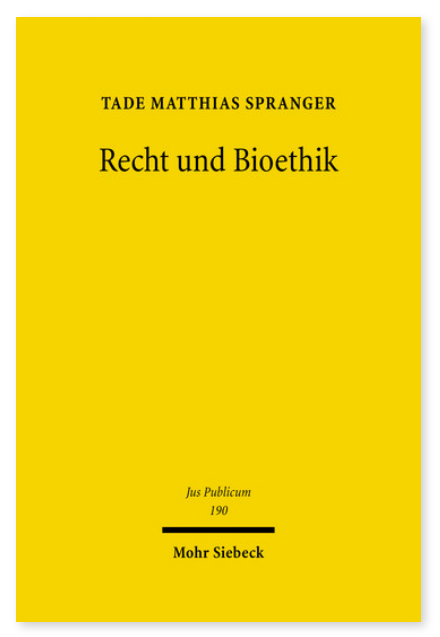

2010. XVI, 445 Seiten. JusPubl 190

ISBN 978-3-16-151271-1

DOI 10.1628/978-3-16-151271-1

eBook PDF 144,00€

ISBN 978-3-16-150328-3

Leinen $144,00 €$
Obwohl umfassendere Kodifizierungsprozesse zu den Lebenswissenschaften erst seit etwa zwanzig Jahren zu registrieren sind, wurde in dieser vergleichsweise kurzen Zeit bereits ein dichtes Netz spezifischer Regulierungen geschaffen. Dabei lässt sich der Umstand, dass die jeweiligen Regelungsgegenstände sowohl unter rechtlichen als auch unter bioethischen Gesichtspunkten Gegenstand der Diskussion sind, häufig auch im Ergebnis des Regulierungsprozesses ablesen. Bioethische Prinzipien entfalten so nicht mehr nur norminitiierende oder normkonkretisierende, sondern auch unmittelbar positivrechtliche Effekte; Risiken ergeben sich hieraus für den Normunterworfenen oder -anwender, aber auch hinsichtlich einer möglichen Instrumentalisierung ethischer Reflexion. Vor diesem Hintergrund befaßt sich Tade Matthias Spranger mit dem Begriff der Bioethik im Kontext nationaler, europäischer und internationaler Rechtssetzung und Rechtsprechung und unterzieht diese einer kritischen Bewertung.

Tade M. Spranger Geboren 1971, Studium der Rechtswissenschaft in Bonn, 1997 Promotion zum Dr. iur. und 2002 zum Dr. rer. pol., seit 2006 Leiter der BMBF-Forschungsgruppe »Normierung in den Modernen Lebenswissenschaften« am Institut für Wissenschaft und Ethik, 2008 Habilitation; seit 2009 Privatdozent an der Rechts- und Staatswissenschaftlichen Fakultät der Rheinischen Friedrich-Wilhelms-Universität Bonn.

Jetzt bestellen:

https://mohrsiebeck.com/buch/recht-und-bioethik-9783161512711?no_cache=1

order@mohrsiebeck.com

Telefon: +49 (0)7071-923-17

Telefax: $+49(0) 7071-51104$ 